due to some genetic relation between the two organisms, the one producing the other at various times and in divers places in the same way as the normal Linaria vulgaris from time to time and in this spot and the other produces the peloric form? Have we caught one species in the act of producing another?

E. F.

\section{EXPERIMENTAL MORPHOLOGY.}

Einleitung in der experimentelle. Morphologie der Tiere. By Dr. Hans Przibram. Pp. I42. (Leipzig and Vienna: Franz Deulicke, 1904.) Price 4 marks. THIS volume is divided into thirteen practically 1 independent sections, and represents the "fast unveränderte Drucklegung " of a course of lectures delivered by the author during the session of $1903-4$ at the Wiener University. The author has been induced to publish these lectures by the belief that all previous works of a general nature dealing with experimental embryology have either been written wholly in support of particular theories (e.g. Driesch, Haacke, Herbst) or only deal with a portion of the subject (e.g. Davenport, Hertwig, Korschelt, Maas, Morgan, Wilson, Ziegler). The present work is intended, therefore, as an introduction to the whole subject from an impartial standpoint.

In the first section, which deals mainly with the scope of experimental morphology, the author, after weighing the various names which have been proposed for the science-Entwicklungsmechanik, Entwicklungsphysiologie, kausala Morphologie, \&c. -adopts Davenport's name, "experimental morphology," but defines it as including not only the experimental study of the factors determining form in ontogeny, but also in phylogeny (Umvandlungsphysiologie), so that Driesch's term "rationelle Morphologie" would seem to be more appropriate.

The uncertainty as to the proper scope of the science which this considerable choice of names exhibits is in part due to its recent growth, but it is also due in no small measure to the close connection in which experimental morphology must always stand to the other sciences.

That the author has not been more successful than his predecessors in determining suitable limits to the subject is very clearly shown by his treatment of the section dealing with the "Specifische Bestimmung." In this section the author describes the influence of relationship in transplantation experiments, and the persistence of specific characters in the transplanted tissues. He then refers to Heape's experiment, in which normal development of an Angora rabbit is obtained, though transplanted shortly after fertilisation into the uterus of a Belgian rabbit, from which, however, the author's conclusion that transfusion of strange blood has no morphogenic influence hardly follows. Following this is an account of immunity and blood relationship experiments. If it is difficult to see why these subjects should be included in a science ostensibly dealing with the factors determining form, this difficulty is still greater when the author proceeds to consider the distribution in the NO. 1870 , VOL. 72$]$ animal kingdom of the various proteid substances contained in muscle fibre.

In the fourth section, "Die Bewegung-Taxis," the author gives a series of very far-fetched comparisons between the behaviour of unicellular animals and of the higher Metazoa. The sensation of thirst is compared with the hydrotaxis of the Mycetozoa, and Davenport's example is followed in regarding as rheotaxis the behaviour of fish in swimming against the stream, the only position in which they are able to breathe. Finally, the "Thigmotaxis" exhibited by an oxytrocha moving round a spherical egg, unable to leave its surface, is compared with the retreat of a cat into the corner as a dog approaches, or to the preference shown by many people for those seats in a restaurant which have their backs to the wall!

In the twelfth section, "Die Vererbung," the author, after giving a brief account of the current theories of heredity, shows how these are in "schönster Uebereinstimmung" with our recent knowledge concerning the constitution of the nucleus. This agreement is obtained by assuming reduction to consist in the elimination of whole chromosomes during the maturation divisions, the view that this process represents the belated union of the paternal and maternal chromosomes not being mentioned.

In the final section, "Die Artwandlung," the author discusses the influence of external factors in causing transmissible variations.

The wide range covered by the book, the thirteen sections of which only average ten pages each, has resulted in a somewhat superficial mode of treatment, and neither in point of comprehensiveness nor of impartial treatment can the book be said to fill the want which, according to the author, has been left unsatisfied by all previous workers. G. C. C.

\section{ATLAS OF EMISSION SPECTRA.}

Atlas of Emission Spectra of most of the Elements. By Drs. Hagenback and Konen. English translation by Dr. A. S. King. Pp. $v+70$ and plates. (Jena: G. Fischer; London: Wm. Wesley and Sons, 1905.) Price $27 s$.

HIS atlas comprises the results of an investigation of the spark, arc, and flame spectra of most of the chemical elements. Twenty-eight charts are given showing heliographic reproductions of photographs taken with the aid of two small Rowland concave gratings, each of I metre radius and 20,000 lines to the inch. One of the gratings had a ruled space $9 \mathrm{~cm}$. broad, and was used chiefly for the region of shorter wave-length. The other had a breadth of $5 \mathrm{~cm}$., and was used to photograph the less refrangible portion of the spectrum. For each group of metals two charts are given, one showing the normally visual part of the spectrum, the other the violet and ultra-violet region. The dispersion given by the gratings is such that the length of spectrum from the $\mathrm{K}$ line of calcium $(\lambda$ 3934) to the $\mathrm{D}$ lines of sodium $\left(\lambda 5^{893}\right)$ is about 4.5 inches, or II cm., each scale division on the reproductions corresponding to 